\title{
To be or not to be the odd one out - Allele- specific transcription in pentaploid dogroses (Rosa L. sect. Caninae (DC.) Ser)
}

\author{
Christiane M Ritz ${ }^{1 *}$, Ines Köhnen², Marco Groth ${ }^{3}$, Günter Theißenn ${ }^{4}$, Volker Wissemann ${ }^{5}$
}

\begin{abstract}
Background: Multiple hybridization events gave rise to pentaploid dogroses which can reproduce sexually despite their uneven ploidy level by the unique canina meiosis. Two homologous chromosome sets are involved in bivalent formation and are transmitted by the haploid pollen grains and the tetraploid egg cells. In addition the egg cells contain three sets of univalent chromosomes which are excluded from recombination. In this study we investigated whether differential behavior of chromosomes as bivalents or univalents is reflected by sequence divergence or transcription intensity between homeologous alleles of two single copy genes (LEAFY, CGAPDH) and one ribosomal DNA locus (nrlTS).
\end{abstract}

Results: We detected a maximum number of four different alleles of all investigated loci in pentaploid dogroses and identified the respective allele with two copies, which is presumably located on bivalent forming chromosomes. For the alleles of the ribosomal DNA locus and CGAPDH only slight, if any, differential transcription was determined, whereas the LEAFY alleles with one copy were found to be significantly stronger expressed than the LEAFY allele with two copies. Moreover, we found for the three marker genes that all alleles have been under similar regimes of purifying selection.

Conclusions: Analyses of both molecular sequence evolution and expression patterns did not support the hypothesis that unique alleles probably located on non-recombining chromosomes are less functional than duplicate alleles presumably located on recombining chromosomes.

\section{Background}

Polyploidisation is considered to be a major creative force in plant evolution since approximately $70 \%$ of angiosperm lineages underwent whole-genome duplications during their evolution [1]. In most cases genome doubling comes along with interspecific hybridization (allopolyploidy) and the genetic outcomes of these combined events are manifold and not easy to predict $[1,2]$. In principle the evolutionary fate of duplicated genes, including homeologs generated by polyploidization, can result in 1) the retention and co-expression of all copies, 2) loss or silencing of some copies (non-functionalisation), 3) development of complementary copy-specific functions (sub-functionalisation) and 4) divergence

\footnotetext{
* Correspondence: christiane.ritz@senckenberg.de

'Department of Botany, Senckenberg Museum of Natural History Görlitz, Am Museum 1, D-02826 Görlitz, Germany

Full list of author information is available at the end of the article
}

between copies leading to acquisition of new functions (neo-functionalisation) [3,4]. In case of co-expression of duplicated genes allopolyploids have to cope with negative effects of increased gene dosage, thus most genes are expressed at mid-parent levels [5,6]. The potential for reprogramming of genetic systems increases the plasticity to react on changing environments, buffers the effect of deleterious mutations and is probably responsible for the evolutionary success of polyploids [7]. A disadvantageous effect of polyploidy is the possible disturbance of meiosis by doubled chromosomes which may prevent correct bivalent formation [7]. However, newly formed allopolyploids can maintain sexual reproduction in the majority of cases because stable bivalent formation during meiosis is enhanced by the divergence between homeologous chromosomes. Contrary, the establishment of anorthoploid (odd ploidy) hybrids is based on asexual reproduction, e. g. in Crepis L., Rubus 
L. and Taraxacum F.H. Wigg [8]. Peculiar exceptions among these anorthoploids are the mostly pentaploid sexual European dogroses (Rosa L. sect. Caninae (DC.) Ser.). Section Caninae originated by multiple hybridization events [9] and overcame the sterility bottleneck due to odd ploidy by the development of a unique meiosis mechanism regaining sexual reproduction [10-13]. This meiotic system is unique in plants, but other meiosis systems leading to comparable effects have been observed e.g. in the sexual triploid plant Leucopogon juniperinus R.Br. (Ericaceae) [8] and the triploid hybrid fish Squalius alburnoides [14]. High ploidy levels and sexuality have probably been the prerequisites for the evolutionary success of dogroses after the retreat of Pleistocenic ice shields, because dogroses are very widely spread in Central Europe and occur on a broad range of different habitats, whereas diploid and tetraploid species of other sections of Rosa are mainly found in glacial refugia [15].

The so-called canina-meiosis produces haploid pollen grains $(n=x=7)$ and tetraploid egg cells $(n=4 x=28)$ which merge to pentaploid zygotes $(2 n=5 x=35$; Figure 1). A very similar process is observed in tetraploid dogroses $(2 \mathrm{n}=4 \mathrm{x}=28)$, which form also haploid pollen grains $(n=x=7)$ but triploid egg cells $(n=3 x=21)$. Bivalent formation and thus recombination occurs always between chromosomes of the same two highly homologous sets, one transmitted by the pollen grain and the other by the egg cell. The remaining chromosomes are exclusively transmitted by the egg cell and do

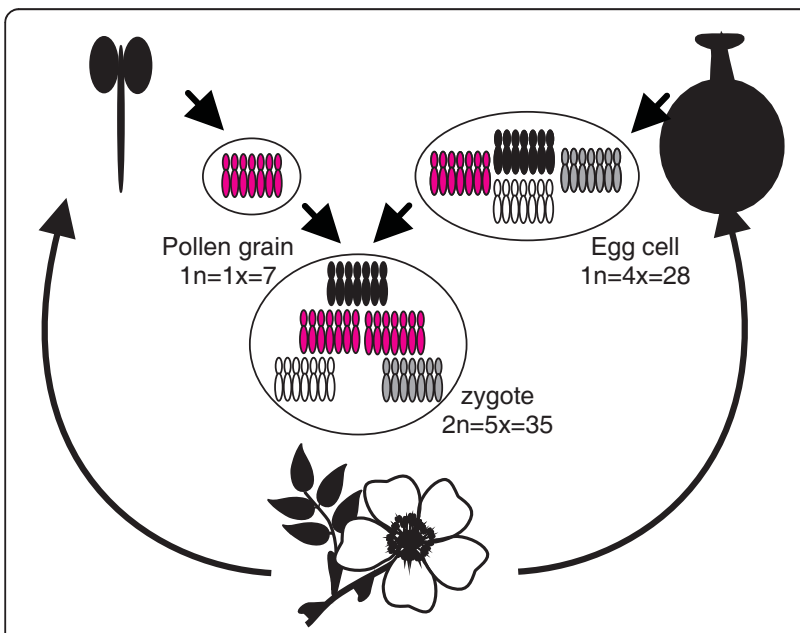

Figure 1 Diagram of canina meiosis. Dogroses with a pentaploid somatic chromosome number $(2 n=5 x=35)$ produce haploid pollen grains $(1 \mathrm{n}=1 \mathrm{x}=7)$ during microsporogenesis in the anthers and tetraploid egg cells $(1 n=4 x=28)$ during megasporogenesis in the carpels. Fertilization of haploid pollen grains and tetraploid egg cells restores the pentaploid somatic level of the next generation. Bivalent forming chromosomes are presented in red, univalent chromosomes are presented in white, grey and black. not undergo chromosome pairing [16-18]. Thus, caninameiosis unites intrinsically sexual reproduction (recombining bivalents) and apomixis (maternally transmitted unrecombined univalents). Previous studies demonstrated that the number of different nuclear ribosomal DNA families and microsatellite alleles was always lower than the maximum number expected from ploidy level of investigated plants, thus one allele is always present in at least two identical copies [9,16-19]. Research on artificial hybrids revealed that alleles with identical copies are located on bivalent forming chromosomes and refer probably to an extinct diploid Proto-Caninae ancestor, whereas the copies located on univalents are more diverged between each other $[9,16,17,19]$. Studying expression patterns of rDNA loci within five different dogrose species Khaitová et al. (2010) observed stable expression patterns of rDNA families on bivalentforming genomes in contrast to frequent silencing of rDNAs from univalent-forming genomes [20].

In this study we wanted to determine whether the differential behaviour of chromosomes during meiosis is mirrored in gene divergence and expression patterns of homeologs by the analysis of three marker genes in Rosa canina L. Therefore, we analysed the extent of molecular divergence between alleles of two single copy genes: $L E A F Y$ and cytosolic glyceraldehyde 3-phosphate dehydrogenase ( $c G A P D H)$; and between families of nuclear ribosomal internal transcribed spacers (nrITS-1). $L E A F Y$ encodes a transcription factor which controls floral meristem identity [21] and $c G A P D H$ encodes an essential enzyme of glycolysis. Nuclear ribosomal ITS is part of the 18S-5.8S-26 S ribosomal DNA cluster, which is organized in long tandem arrays in one nucleolus organizer region (NOR) per genome in dogroses [22,23]. The apparent absence of interlocus homogenization between NORs $[19,24]$ allows tracking different dogrose genomes by diagnostic ITS families $[9,19,25]$. The sequence information obtained from the homeologs of the three marker genes was then used for allele-specific transcription analyses using pyrosequencing.

\section{Results}

Gene copy numbers

Southern hybridizations were performed to estimate the copy numbers of $L E A F Y$ and $c G A P D H$ in Rosa canina (additional file 1). One to three fragments were detected in the digestions of genomic DNA by six different enzymes hybridized against probes of $L E A F Y$ or $c G A P D H$. The maximum number of three fragments within the digestions did not contradict against the expectation for $L E A F Y$ and $c G A P D H$ to have one copy per each dogrose genome, because we expected a maximum number of five bands in pentaploids. Variation in the observed one to three bands result either from 
restriction sites of the enzymes HincII and HindIII within the range of the probe for some of the alleles or from variation of the number of cutting sites between dogrose genomes.

\section{Allelic variation}

We sequenced approximately 1990 bp of $L E A F Y$ in seven individuals of Rosa canina; only the first about $50 \mathrm{bp}$ downstream of the translation start codon and the last about $50 \mathrm{bp}$ upstream of the stop codon were missing. We detected four different alleles of $L E A F Y$ termed $L E A F Y-1,-2,-3$ and -4 (Figure 2). We did not sample the allele $L E A F Y-4$ directly by cloning analysis in the individuals $\mathrm{H} 21,194$ and 378 , but we detected it with the help of PCR using LEAFY-4 -specific primers (data not shown). Genomic sequences of alleles differed between each other by $0.07 \%-4.1 \%$; their coding sequences contained no premature stop codons and 29 amino acid substitutions in total (Table 1). The analysed plants were pentaploid implying that one of the $L E A F Y$ alleles had two copies, which was allele $L E A F Y-3$ determined by pyrosequencing of an allele-specific single nucleotide polymorphism (SNP) in genomic DNA (Figure 3).

We isolated approximately $2100 \mathrm{bp}$ of the $c G A P D H$ sequence in five individuals of $R$. canina; only the first about 120 bp downstream of the translation start codon and the last about $120 \mathrm{bp}$ upstream of the stop codon were missing. We found four different alleles of $c G A P D H$ in individual $\mathrm{H} 20$ and three different alleles in the other individuals (Figure 4). Using allele-specific primers the allele $c G A P D H-2$ could be detected in all individuals but the allele $c G A P D H-4$ only in individual H20 (data not shown). Genomic sequences of alleles were very similar to each other $(0.08-2.42 \%$ sequence divergence) and we detected only five amino acid substitutions and no premature stop codons in the coding region (Table 1). Allele frequency determination of genomic DNA indicated that allele $c G A P D H-1$ has three copies in H13 and H19 and two copies in H2O (Figure 5).

We identified three different alleles of nrITS in the plants $\mathrm{H} 13$ and $\mathrm{H} 20$ and four alleles in H19 (Figure 6). The alleles Canina-1, Rugosa and Woodsii were identical to sequences found in a previous study [9], but allele Canina-2 was sampled for the first time. Whereas in case of $L E A F Y$ and $c G A P D H$ the same allele was present in multiple copies in all plants we observed that the two closely related alleles Canina-1 and Canina-2 (Figure 6) had several copies. We determined three copies of the Canina-1 allele in H13 and H20. We concluded from base frequencies at the SNPs measured in the genomic DNA samples of H19 that this individual had two copies of the Canina-2 and one copy of the Canina-1 allele.
However, base frequency at SNP 4 specific for the Canina-1 and Canina-2 allele is higher (0.778) than expected (0.6; Figure 7, additional file 2).

In all three marker genes we hardly observed any variation between sequences of one clade isolated from different individuals (referred as alleles, Figures 2, 4, 6). Within the $L E A F Y-2$ and $L E A F Y-3$ clade sequences of two individuals formed statistically supported sub-clades (Figure 2). Sequences of $L E A F Y-3 \mathrm{H} 20$ and $\mathrm{H} 21$ differed from the remaining $L E A F Y-3$ sequences by one substitution in intron 3; sequences of $L E A F Y-2 \mathrm{H} 19$ and 378 differed by one synonymous substitution in the coding region and three substitutions in the non-coding region. Following a strict definition these sequences have to be treated as different alleles. However, for pragmatic reasons we decided to summarize them as $L E A F Y-2$ and $L E A F Y-3$ alleles, respectively, because sequences were very closely related and the individuals contained only one of the respective alleles. Tree topologies based on genomic sequences (Figures 2, 4) were identical to those based on coding regions only, but posterior probabilities were higher using genomic sequences (data not shown). In order to investigate the differential evolution between alleles present in multiple copies and single copy alleles we estimated the relative rate of substitutions between different alleles of $L E A F Y$ and $c G A P D H$ by Relative Rate Test (RRT), but no pair of sequences rejected the null hypothesis of equal branch lengths for all alleles (additional file 3). Selection analyses using codeml (PAML) revealed that alleles of $L E A F Y$ and $c G A P D H$ evolved under purifying selection (Table 1). In both genes the models assuming different selective regimes between alleles with multiple copies and singly copy alleles were not significantly better than the null hypothesis (same selective regime for all alleles; data not shown).

\section{Allele-specific transcription}

We found five SNPs in the coding region of $L E A F Y$, three SNPs of $c G A P D H$ and five SNPs of nrITS which were specific for a certain allele and suitable for allele frequency determination by pyrosequencing (additional file 4). We compared the frequency of allele specific bases between samples from cDNA pools and genomic DNA to estimate the relative level of transcription for each allele. Base frequencies obtained from genomic DNA indicate the copy number of an allele and represent the null hypothesis (equal transcription for all alleles with regard to their copy number). The frequency of the allele-specific bases in cDNA-pools did not vary between plants (with regard to the copy number of this allele in a plant) and between small and large flower buds (data not shown).

In $L E A F Y$ the frequency of the allele-specific bases of all investigated SNPs differed significantly from the null 


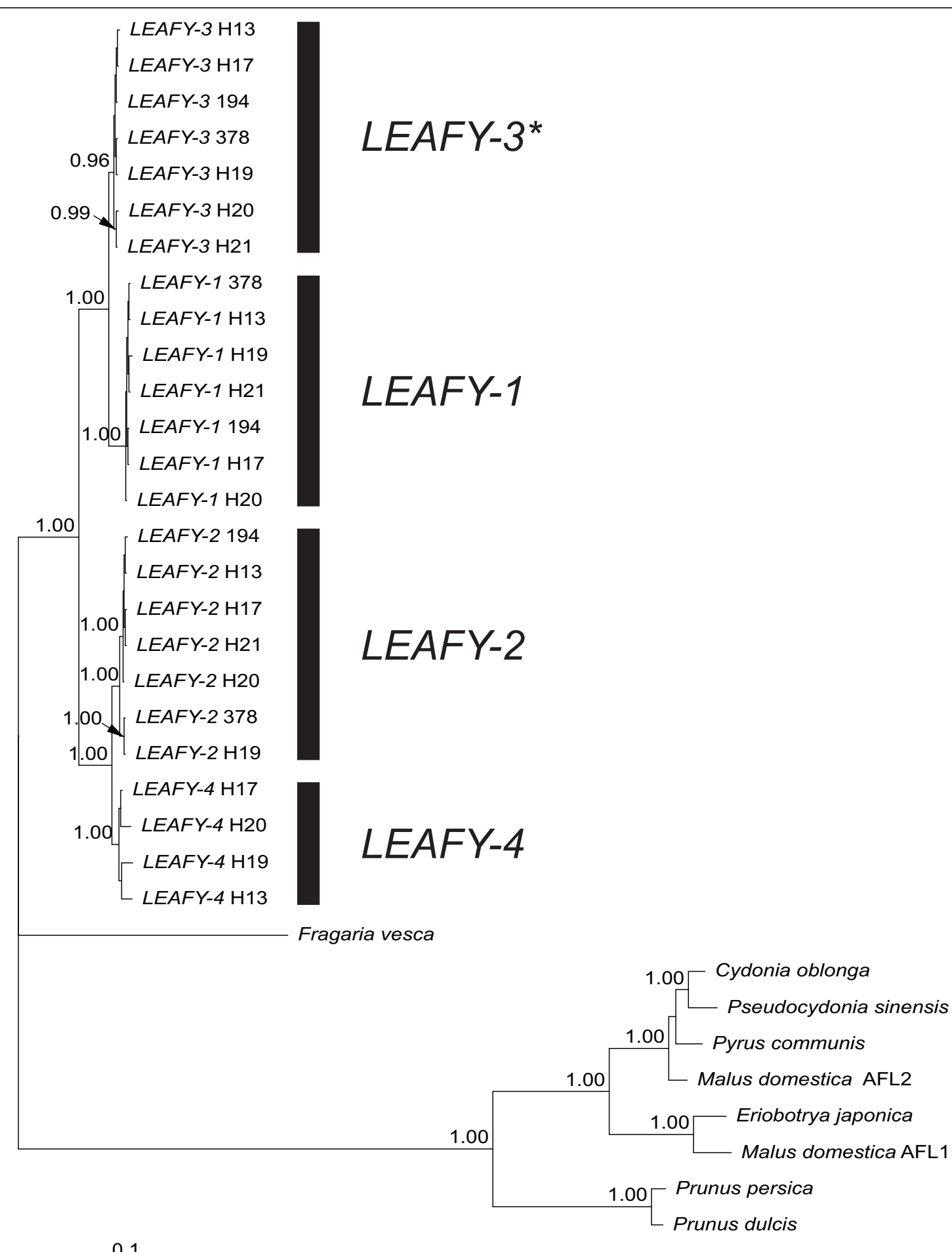

Figure 2 Phylogeny of LEAFY. Bayesian inference of phylogeny for different alleles of LEAFY in Rosa canina based on an alignment of genomic sequences (alignment length $=2280$ bp). Posterior probabilities are given above branches. The allele LEAFY-3 marked with an asterisk has two copies in the plants $\mathrm{H} 13, \mathrm{H} 19$ and $\mathrm{H} 2 \mathrm{O}$. 
Table 1 Number of synonymous and non-synonymous substitutions in the alignments of the coding region of LEAFY and CGAPDH and parameter estimates for the null hypothesis $(\mathrm{HO})$ of the selection analyses (one $\omega$ for all alleles) employed to codeml within PAML

\begin{tabular}{lll}
\hline Gene & LEAFY & cGAPDH \\
\hline Length of coding region* & 1119 & 789 \\
No. of synonymous substitutions & 21 & 4 \\
No. of non-synonymous substitutions & 8 & 1 \\
Indels & 2 & - \\
Parameter estimate for HO (one $\omega$ for all alleles) & $\mathrm{dS}=0.1126, \mathrm{dN}=0.0190, \omega=0.1688$ & $\mathrm{dS}=0.0277, \mathrm{dN}=0.0074$ \\
& $\mathrm{InL}=-1715.88, \mathrm{k}=1.472$ & $\omega=0.2666$ \\
& & $\ln =-1023.59, \mathrm{k}=1.559$
\end{tabular}

*Sequences of coding region are not complete, approximately 50 bp are missing in LEAFY and approximately 120 bp are missing in cGAPDH at both ends to start and stop codon, respectively.

hypothesis (Figure 3, additional file 2). Transcription level of the allele $L E A F Y-3$ with two copies in all investigated plants was 2.3-fold lower, but transcription levels of single copy alleles $L E A F Y-1$ and $L E A F Y-4$ was approximately 2.9-fold higher than expected (Figure 3). We could not estimate the transcription level of $L E A F Y$ 2, because no suitable SNP was available.

Contrary to the results of $L E A F Y$, transcription of cGAPDH-1 with three copies in plants $\mathrm{H} 13$ and H19 and two copies in $\mathrm{H} 20$ was 1.2-fold higher than expected under the null hypothesis (Figure 5, additional file 2). Base frequency of allele $c G A P D H-2$ with presumably one genomic copy was slightly lower than expected, but the difference was only marginally significant. Transcription level of allele $c G A P D H-3$ was significantly higher than expected from genomic DNA. Transcription of $c G A P D H-4$ sampled only in plant $\mathrm{H} 20$ could not be analysed, because we detected no specific SNP in the coding region suitable for pyrosequencing.

In $n$ rITS we did not observe significant differences between the frequency of allele-specific bases of cDNApools and genomic DNA in any of the alleles, so that the null hypothesis of equal transcription was not rejected (Figure 7, additional file 2).

\section{Discussion}

In this study we investigated by the analysis of two single copy genes and one ribosomal DNA locus, whether sequence divergence and transcription levels differ between homeologous nuclear genes in pentaploid Rosa canina. We were interested to determine whether the fate of a homeolog depends on its copy number and thus very likely on whether it is localized on bivalent forming chromosomes undergoing recombination, or on univalent chromosomes, which are transmitted "apomictically" (without recombination) to the offspring in dogroses.

\section{Sequence divergence between alleles}

We detected a maximum number of four different alleles in the analysed genes in pentaploid Rosa canina (Figures 2, 4, 6) suggesting that at least one allele has two or more identical copies, which is in accordance with previous research [9,16-20]. These studies based on rDNA loci and microsatellites from different linkage groups demonstrated that the alleles with identical copies were always transmitted by pollen grains and egg cells and therefore must be located on bivalent forming chromosomes, whereas the remaining alleles are exclusively maternally inherited via univalent chromosomes. It is assumed that chromosome sets forming bivalents refer to a probably extinct diploid Proto-Caninae progenitor characterized by the Canina-ITS type (Figure 6) so far solely found in polyploid dogroses (referred to as $\beta$ clade in $[9,19,20]$ ). However, this unique nrITS type might also have arisen by mutation as shown for the hybrid-specific rDNA units in Nicotiana allopolyploids [26]. The preservation of homeologs in dogroses is not exceptional and has often been used to track the hybridogenic origin of allopolyploids, e.g. [27-30]. However, loss of homeologs has been observed in other very recently evolved hybridogenic species [31-35]. These cases of massive gene loss are mainly documented in herbaceous plants, while dogroses are woody and have much longer generation times. Our data correspond with the situation found in allotetraploid cotton for which gene loss seems not to be a common phenomenon accompanying allopolyploidy [36].

The results found for the nrITS region are comparable but more complicated than those of the single copy genes $L E A F Y$ and $c G A P D H$, because nrITS is part of a gene family, large tandem repeats of ribosomal DNA loci, whose copies are normally homogenized by mechanisms of concerted evolution [37]. However, in dogroses homeologous rDNA clusters are also preserved, because sequences are mainly homogenized within one locus but not between loci $[22,23]$. In contrast to this, some rDNA families were physically lost, degenerated or were overwritten by more dominant ones in other well studied allopolyploid systems [38-41].

During our analyses we found very few chimeric sequences $(<5 \%)$ and all of them were unique, thus 


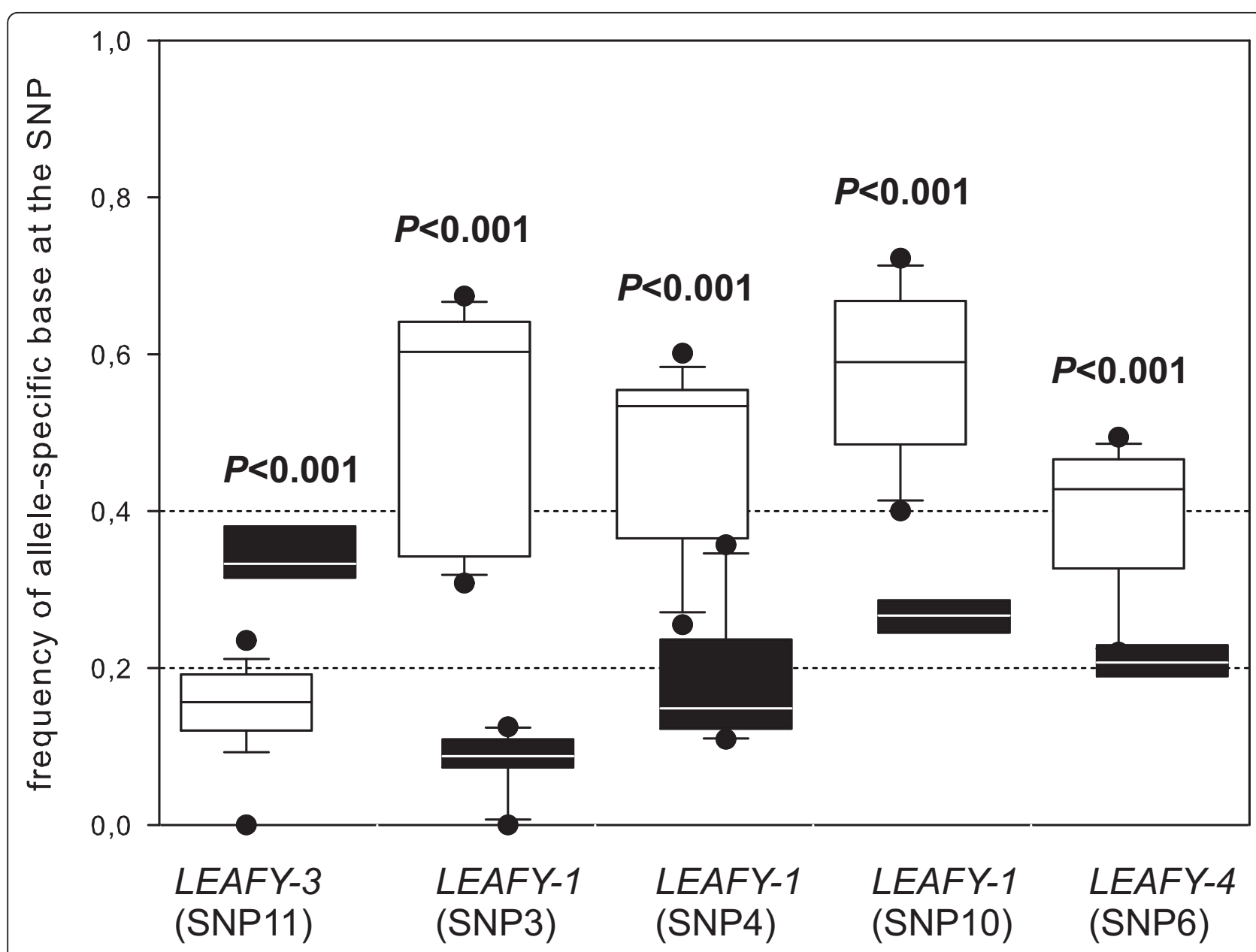

\section{proposed allelic configuration}

\section{plants $\mathrm{H} 13, \mathrm{H} 19, \mathrm{H} 20 \quad 2 \times(L E A F Y-3)$ : LEAFY-1 : LEAFY-2 : LEAFY-4}

Figure 3 Allele-specific transcription of LEAFY. Frequency of allele-specific bases for five SNPS in PCR products from genomic DNA and from CDNA pools of small and large flower buds were obtained by pyrosequencing for the plants $(H 13, \mathrm{H} 19, \mathrm{H} 20)$ and are presented as boxplots consisting of sample minimum, lower quartile, median, upper quartile and sample maximum. Black boxes refer to genomic DNA, white boxes to cDNAs. Dotted lines represent the proposed frequency of an allele-specific base in genomic DNA and the null hypothesis of equal transcription for all alleles referring to their copy number: Alleles with one copy have an expected frequency 0.2; alleles with two copies have an expected frequency of 0.4 in pentaploids. Allele LEAFY-3 has two copies, alleles LEAFY-1 and LEAFY-4 have one copy. P-values of GLM statistics (additional file 2) comparing base frequencies of genomic and CDNA pools at a SNP are given above boxplots. Significant results are presented in bold. We did not find an allele-specific SNP for LEAFY-2 suitable for pyrosequencing analysis, but sampled this allele in all individuals from genomic DNA.

these sequences originated most likely by stochastic PCR recombination [42]. This apparent absence of recombinant alleles is concordant with the study of Khaitová et al. (2010) [20] in dogroses and corresponds with results from Nicotiana demonstrating that recombination between nuclear glutamine synthetase sequences occurred in diploid but not in allopolyploid Nicotiana hybrids [30]. In contrast, recombinant alleles between progenitor sequences were observed in allopolyploid Gossypium [43] and Tragopogon [44].

In none of the investigated genes we observed signs of loss of function for homeologs (e.g. premature stop codons, deviating GC content; see also [9]). Moreover, relative rate tests for $L E A F Y$ and $c G A P D H$ did not detect differential rates of sequence evolution between alleles of one locus. Selection analyses revealed that all 


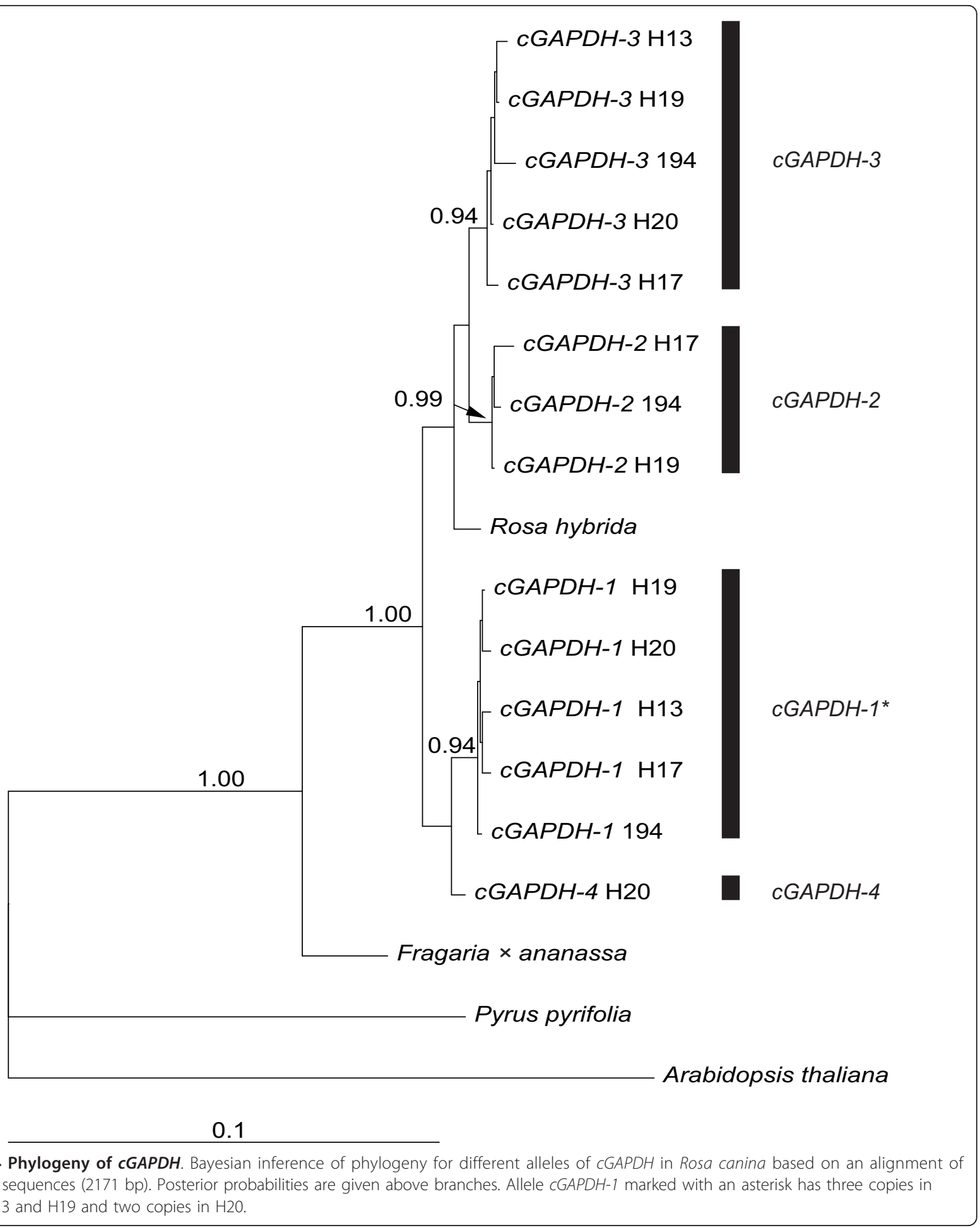

homeologs evolved under purifying selection and did not detect differential selective regimes between them (Table 1). These results suggest that all homeologs of investigated loci are fully functional. However, only eight non-synonymous substitutions in $L E A F Y$ and only one non-synonymous in $c G A P D H$ (Table 1) were observed, so that sequence divergence might not suffice to detect different selective regimes.

\section{Differential transcription of homeologous alleles}

All homeologs of the marker genes investigated here were co-expressed, but transcription levels deviated 


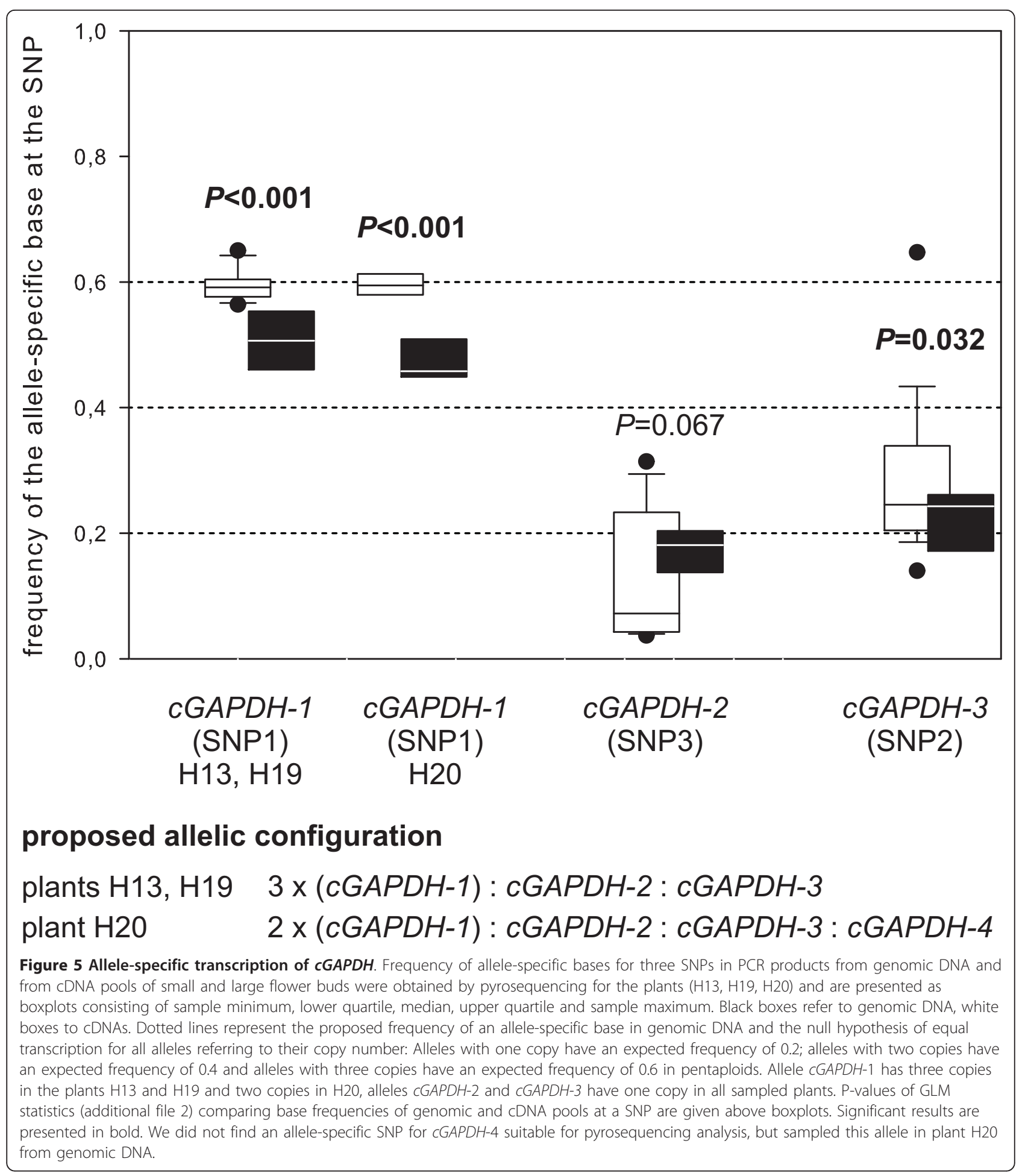

from values expected from genomic copy number for many homeologs. Co-expression has been observed for the majority of homeologous genes in allopolyploid systems [5]. We found no evidence for complete epigenetic silencing of a homeolog, which has been reported for cGAPDH and ribosomal DNAs in allotetraploid
Tragopogon [32] and for nrITS in several other pentaploid dogrose species [20].

Differences in transcription level were most strongly pronounced in $L E A F Y$ displaying a significantly lower transcription for $L E A F Y-3$ with two genomic copies and a higher transcription for homeologs with one 


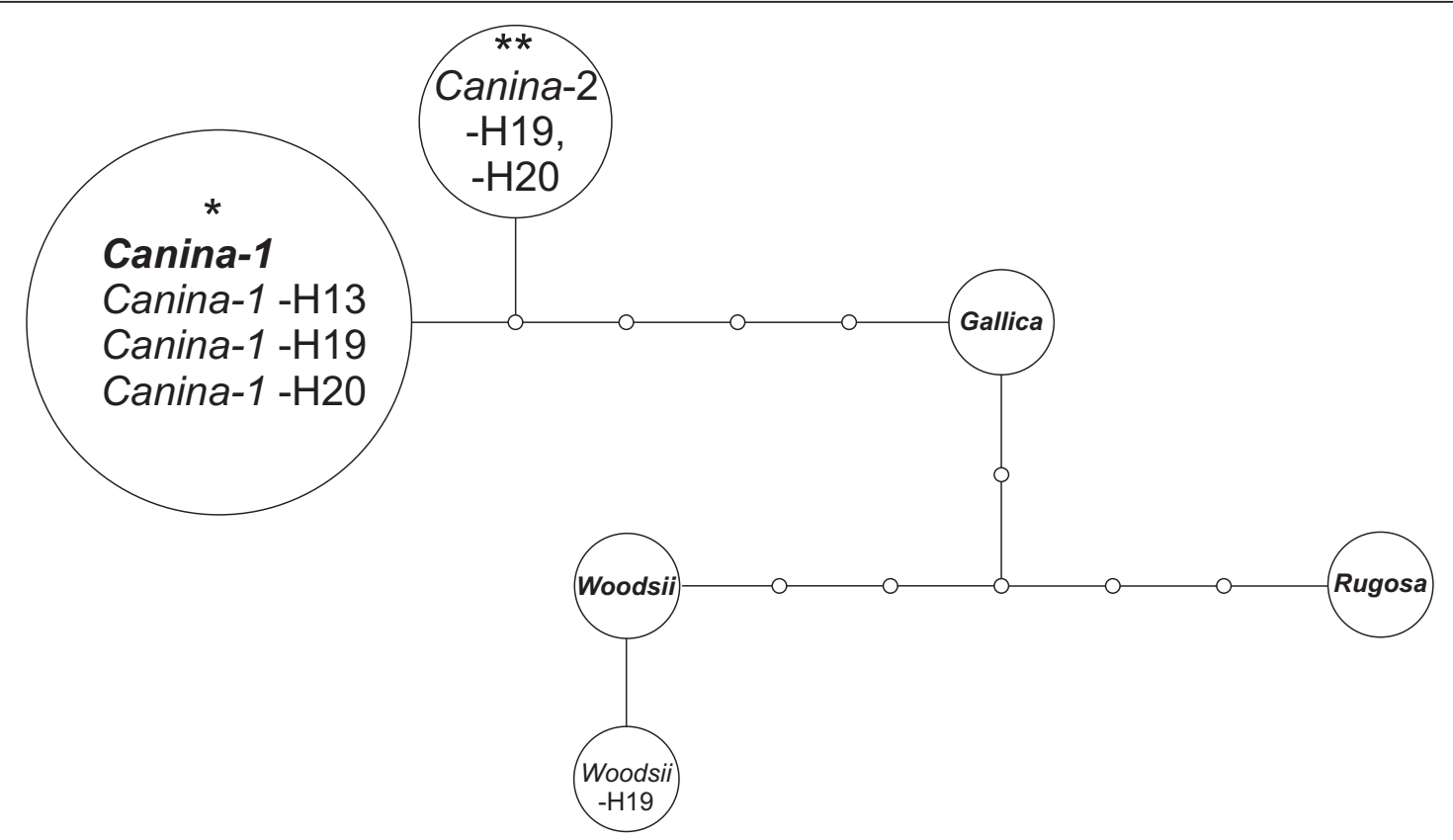

Figure 6 Haplotype network of nrITS-1. Haplotype network of nrlTS-1 sequences of Rosa canina based on an alignment (254 bp) including consensus sequences of different nrlTS-1 types (bold font) taken from [9]. The allele Canina-1 marked with an asterisk had three copies in $\mathrm{H} 13$ and $\mathrm{H} 2 \mathrm{O}$, the allele Canina-2 marked with two asterisks had two copies in H19. Pyrosequencing revealed that all individuals contained one Rugosa allele (Figure 7).

copy than expected from the copy number (Figure 3). We observed contrary but less pronounced results for $c G A P D H$. Alleles with two or more copies were more strongly expressed than expected from genomic copy number (Figure 5). For nuclear ribosomal RNA we detected no deviation from the expected transcription level (Figure 7). These results demonstrate that transcription level is not directly related to copy number of alleles. Analogous to results from microsatellites and rDNA loci $[9,16-20]$ we assume that alleles with two copies are located on the bivalent forming chromosomes, even though alternative scenarios cannot be completely ruled out at the moment. Following this assumption our results suggest that there is no general evolutionary fate for a homeolog located on a bivalentor univalent-forming chromosome. Comparable results were obtained in case of the triploid hybrid fish Squalidus alburnoides for which silencing patterns for dosage compensation were rather gene- than genomespecific [14]. According to the above cited studies we presume that $L E A F Y$ homeologs with one copy are located on the univalent chromosomes. The increased transcription of these $L E A F Y$ alleles (Figure 3) provides an example that genetic information from non-recombining genomes is functional and active. This contrasts findings from Nicotiana allopolyploids for which an inverse correlation between silencing and the intensity of inter-genomic recombination has been proposed
[45]. It is a matter of speculation whether the pronounced transcription differences in $L E A F Y$ represents an exception because $L E A F Y$ is an transcription factor expressed in floral organs whereas the two other loci cGAPDH and nrITS are expressed in every tissue, but recent studies demonstrate that gene classification is not a strong predictor for differential expression patterns [46].

Contrary to our results Khaitová et al. (2010), who investigated six different dogrose species based on cleaved amplified polymorphism sequence (CAPS) analysis, concluded that $n$ rITS- 1 copies located on univalent genomes are more frequently silenced than loci from bivalent forming genomes [20]. Using the same marker but pyrosequencing for transcription analysis we did not find any differential transcription of rDNA loci in Rosa canina. However, according to the results of Khaitová et al. 2010, differences in transcription level of rDNA alleles were less pronounced in $R$. canina compared to other dogrose species, e.g. $R$. rubiginosa L. [20]. Differences between the two studies might be caused by the origin of ribosomal RNA, which was extracted from leaves by Khaitová et al. (2010) and from two different stages of flower buds here [20]. Gene expression has shown to be organ-specific $[47,48]$ and varies strongly between leaves and floral tissues in allopolyploids [49]. Moreover, rRNA genes which were silenced in leaves were expressed in floral organs in Brassica [50]. We did 


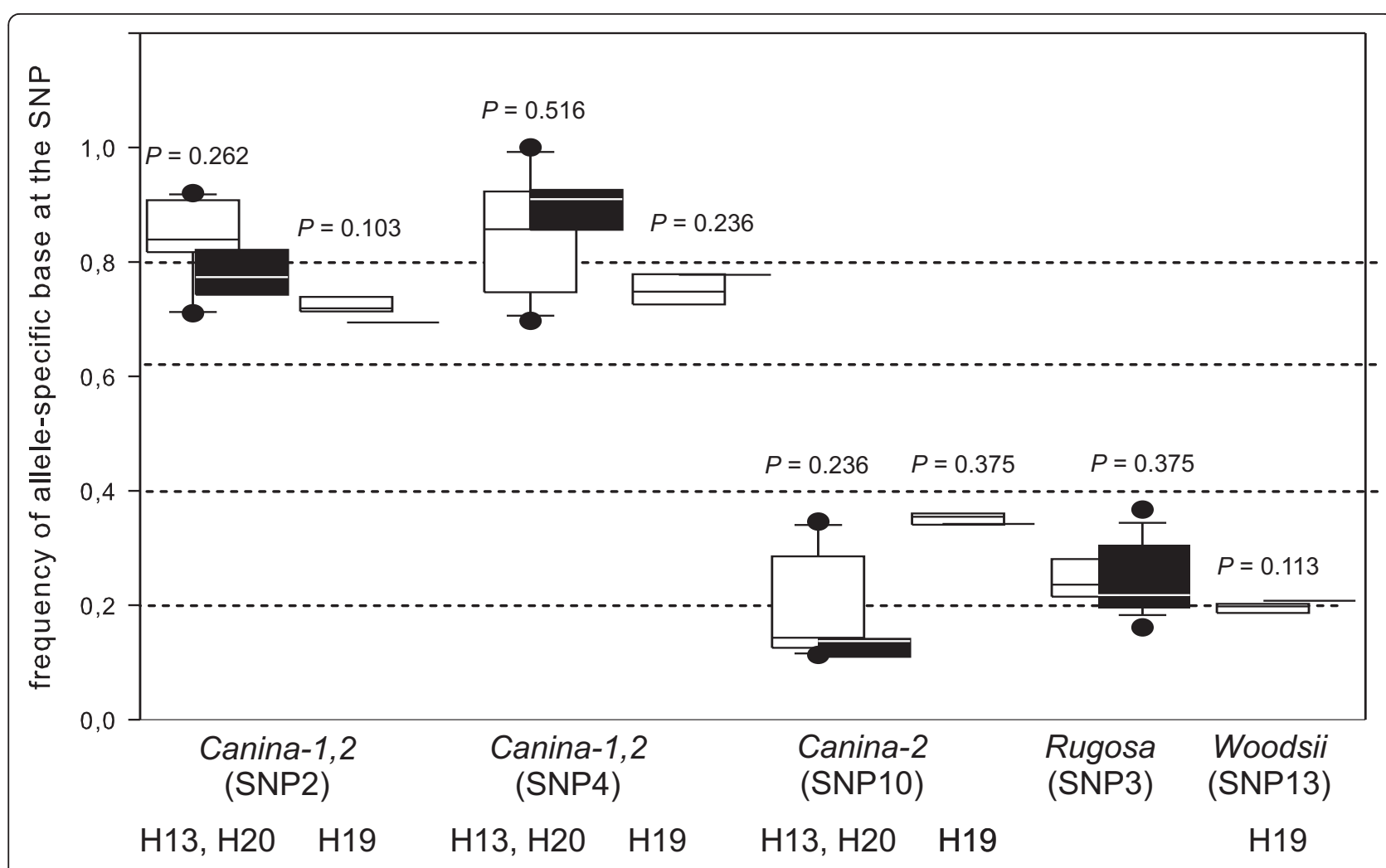

\title{
proposed allelic configuration
}

\author{
plants H13, H20 $3 \times$ (Canina-1): Canina-2 : Rugosa \\ plant $\mathrm{H} 19 \quad 2 \times($ Canina-2) : Canina-1: Rugosa : Woodsii
}

Figure 7 Allele-specific transcription of $\boldsymbol{n r I T S}$. Frequency of allele-specific bases for three SNPs in PCR products from genomic DNA and from CDNA pools of small and large flower buds were obtained by pyrosequencing for the plants $(H 13, H 19, H 20)$ and are presented as boxplots consisting of sample minimum, lower quartile, median, upper quartile and sample maximum. Black boxes refer to genomic DNA, white boxes to cDNAs. Dotted lines represent the proposed frequency of an allele-specific base in genomic DNA and the null hypothesis of equal transcription for all alleles referring to their copy number: Alleles with one copy have an expected frequency of 0.2; alleles with two copies have an expected frequency of 0.4 and alleles with three copies have an expected frequency of 0.6 in pentaploids. SNP2 and SNP4 did not differentiate between the Canina-1 and Canina-2 allele, thus boxplots of genomic DNA summarize the frequency of both alleles. Because allelic composition in the genomic DNA varied between individuals $\mathrm{H} 13, \mathrm{H} 2 \mathrm{O}$ and $\mathrm{H} 19$, results are presented separately. P-values of GLM statistics (additional file 2) comparing base frequencies of genomic and CDNA pools at a SNP are given above boxplots. Significant results are presented in bold.

not find differences in expression patterns between very young and elder flower buds, whereas such developmentally dependent expression patterns were shown in cotton [51]. Our results might also be influenced by the method of reverse transcription. We used oligo-dT primers, which are suited for RNA polymerase II products with polyadenylated 3' ends but the poly(A) stretch is normally absent in functional rRNAs and present in intermediates of a RNA degradation pathway [52]. However, we do not expect a strong impact of these rare degradation products on our results because conditions of reverse transcription were not stringent and rRNAs were highly overrepresented in RNA templates.

\section{Conclusions}

We analysed three marker genes to investigate homeologspecific transcription levels in pentaploid dogroses. Based on previous research we assume that alleles located on bivalent-forming (recombining) chromosomes have identical copies $[16,17,19,20]$. We could show that sequence divergence and transcription intensity is not always strongly correlated with the copy number of alleles. Thus we found no evidence that genetic information on nonrecombining genomes is degraded or less functional than genes from recombining chromosomes. The absence of differential selection between dogrose genomes is surprising because it is assumed that sect. Caninae originated 
during Miocene to Pliocene (approximately 6 Mya) [53] and fossils of rose hips were found in deposits of the Lower Oligocene (approximately 25 Mya) [54]). Contrary, massive gene loss and heavily changed expression profiles have been observed in other very young allopolyploids even after a few generations [31-34]. Despite the preferential pairing of two homologous chromosome sets during meiosis, dogroses are functional diploids in terms of chromosome pairing as suggested by Grant (1971) [8]; however, they are no functional diploids in terms of genome activity, since they transcribe genes and thus use information from all involved genomes. This might be a selective advantage because polyploid dogroses dominate Central European rose populations and repel diploid wild roses towards more or less isolated habitats [15]. Their success could be caused by fixing heterozygosity on univalent genomes on one hand and escaping the evolutionary bottleneck of complete apomixis by maintaining recombination between bivalents on the other hand. The heterogeneous results from our analysis demand further research on the transcriptome of dogroses which considers a broader sampling of species and genes and accounts also for possible tissue-specific differences.

\section{Methods}

\section{Plant Material}

Five individuals of $R$. canina were sampled from a natural population "Himmelreich", Jena, Germany (plants: $\mathrm{H} 13, \mathrm{H} 17, \mathrm{H} 19, \mathrm{H} 20, \mathrm{H} 21$ ), and two individuals of $R$. canina were taken from the dogrose collection at the Botanical Garden Gießen, which were originally collected at the natural population "Einzelberg", Groß Schneen, Germany (plants 194, 378). Voucher specimens have been deposited at the Herbarium Gießen (GIE).

\section{Ploidy Determination}

Flow-cytometry was conducted according to the method described in [55] using a Cell Counter Analyzer CCA II (Partec, Münster, Germany) and Rosa arvensis Huds. (2n = $2 \mathrm{x}=14$ ) as an internal diploid standard. A minimum of 10,000 nuclei giving peaks with a coefficient of variation of approximately $10 \%$ were counted.

\section{DNA and RNA Extraction}

DNA was extracted from young leaf material according to [56]. Total RNA was obtained from small and large floral buds using RNeasy Plant Mini Kit (Qiagen, Hilden, Germany) following the manufacturer's protocol and its modifications described by [57]. First strand cDNA was synthesized by RevertAid ${ }^{\mathrm{TM}} \mathrm{H}$ Minus MMulLV Reverse Transcriptase (Fermentas, St. Leon-Rot, Germany) using an oligo-dT primer.

\section{Sequence determination}

Sequences of LEAFY, cGAPDH and nrITS-1 were obtained from genomic DNA to identify polymorphisms between alleles located on different chromosome sets. Primers for the amplification of $L E A F Y$ were designed from an alignment of cDNAs of $L E A F Y$ of different species of Rosaceae: LFYex1-fwd (5'-CAAGTGGGACCTACGAGGCATGG-3') and LFYex3-rev (5'-TCGGCGT GACAAAGCTGACGAAG-3'). Primers for the amplification of $c G A P D H$ were designed from cDNAs of Rosa chinensis Jacq. and Fragaria $\times$ ananassa (Weston) Rozier taken from Genbank: GPDex2-fwd (5'-GCCAAGATCAAGATCGGAATCAACG-3') and GPDex11-rev (5'-CTCGTTCAATGCAATTCCAGCCTTG-3'). Primers for amplification of nrITS were taken from [58]. PCR was performed in $50 \mu \mathrm{l}$ containing $2 \mu \mathrm{l}$ of undiluted or diluted genomic DNA, 2 units Taq-Polymerase (Fermentas, St. Leon-Rot, Germany), $5.0 \mu \mathrm{l} 10$-fold polymerase buffer (Fermentas), $4.0 \mu \mathrm{MgCl}_{2}(25 \mathrm{mM}), 2 \mu \mathrm{l}$ of each primer $(10 \mu \mathrm{M}), 5.0 \mu \mathrm{l}$ dNTPs $(2 \mathrm{mM})$. The following PCR protocol was performed: initial denaturation cycle of $150 \mathrm{~s}$ at $94^{\circ} \mathrm{C}$, followed by 30 cycles of $30 \mathrm{~s}$ denaturation at $94^{\circ} \mathrm{C}, 60 \mathrm{~s}$ annealing [annealing temperature $\left(\mathrm{T}_{\mathrm{A}}\right): \mathrm{T}_{\mathrm{A}}=58^{\circ} \mathrm{C}$ for $L E A F Y, \mathrm{~T}_{\mathrm{A}}=51^{\circ} \mathrm{C}$ for cGAPDH and $\mathrm{T}_{\mathrm{A}}=48^{\circ} \mathrm{C}$ for nrITS-1], $180 \mathrm{~s}$ extension at $72^{\circ} \mathrm{C}$ and a final extension for $10 \mathrm{~min}$ at $72^{\circ} \mathrm{C}$. Purified PCR-products (Wizard SV Gel and PCR clean up system, Promega, Mannheim, Germany) were cloned into the vectors pGEMT (Promega) or pJET1 (Fermentas). Ligation products were electroporated into $E$. coli JM109 or DH5 $\alpha$. Twenty positive clones of at least two PCR products were sequenced in both directions using the same primers as for amplification and additional internal primers for $L E A F Y$ (LFYex2-fwd: 5'-CAAGAGAAGGAGATGGTTGGGAG-3'and LFYex2-rev: 5'GCTGCTTGGCAATGTTCTGGAC-3') and $c$ GAPDH (GPDex6-fwd: 5'-GTCAATGAGCATGAATACAAGT CC-3' and GPDex6-rev: 5'-GACTTGTATTCATGCTCATTGAC-3'). Sequences of the alleles $L E A F Y-4$, $c G A P D H-2$ and $c G A P D H-4$ were only sampled in some plants. To test for the presence of these alleles in the remaining plants we performed allele-specific PCRs according to the conditions described above using the forward primers (LFYin1-al4-fwd: 5'-GGACATGTAAATAGGTCGAGAATATAT-3', GPDin2-al2-fwd: 5'AGTTTTCGGATTTTGGTTTCGATC-3' and GPDin3al4-fwd: 5'-ATCTTTGATGTTTTCGGAGTTATATG3', respectively) spanning over allele-specific indels in introns. Resulting sequences were assembled and aligned using Bioedit [59]. New sequence information generated within this study was deposited at the EMBL sequence archive under accession IDs FR725963 - FR725973. 


\section{Southern Hybridizations}

To estimate the copy numbers of $L E A F Y$ and $c G A P D H$ $30 \mu \mathrm{g}$ of genomic DNA of plant sample $\mathrm{H} 20$ was digested with either EcoRI, HincII, HindIII, KpnI, PstI or XbaI, separated on $1 \%$ agarose gels and blotted onto positively charged nylon membranes (VWR, Darmstadt, Germany). Membranes were hybridized with 32P- $\alpha$ dATP-labelled $L E A F Y$ or $c G A P D H$ fragments according to NEBlot Kit (NEB, Frankfurt, Germany). Hybridization probes were prepared from PJET1 plasmids by PCR using the primers LFYex2-fwd, LFYex3-rev and GPDx7F [27], GPDex11rev, respectively, under same conditions as above. Gene fragments of $L E A F Y$ produced under these conditions have an expected length of $1200 \mathrm{bp}$ and those of $c G A P D H$ a length of $850 \mathrm{bp}$.

\section{Phylogenetic analyses}

The best fitting model according to the corrected Akaike Information Criterion for each alignment was estimated for exon and intron sequences separately with MrModeltest v. 2.3 [60]. The parameters of the best model for each partition were employed to reconstruct phylogenies of $L E A F Y$ and $c G A P D H$ with MrBayes v.3.1.2 [61], additional file 5). We ran the analyses over $10,000,000$ generations, sampling every $100^{\text {th }}$ generation and discarding the 100,000 trees as burn-in resulting in a $50 \%$ majority rule consensus tree showing all compatible partitions supported by posterior probabilities (PP) for each node. The phylogeny of $L E A F Y$ was rooted with cDNA sequences of Fragaria vesca L. and other species of Rosaceae, phylogeny of $c G A P D H$ with a cDNA sequence of Fragaria $\times$ ananassa and Arabidopsis thaliana L. (Heynh.). Alignments and phylogenies were deposited in Treebase [http://www.treebase.org (study accession: TB2:S11025)].

A phylogenetic network was calculated with TCS v. 1.2.1 [62] for the $n r I T S-1$ sequence data including also consensus sequences of different Rosa nrITS alleles detected in a former study [9] under 95\% connection limit and gaps treated as missing data.

\section{Selection analyses}

Previous studies on microsatellite alleles demonstrated that alleles with two or more copies are involved in bivalent formation $[16,17]$ and thus undergo recombination during meiosis. Therefore, we wanted to investigate whether alleles of $L E A F Y$ and $c G A P D H$ with two or more copies evolve differentially from alleles with one copy. We conducted Maximum Likelihood pairwise Relative Rate Tests (RRT) implemented in the program HyPhy [63] using the Muse-Gaut model (MG94W9 in HyPhy [64] of codon substitution to estimate the relative rates of substitutions between different alleles of $L E A F Y$ and $c G A P D H$, respectively, and out-group sequences from Fragaria. The resulting parameter estimates were compared by a series of Likelihood Ratio Tests (LRT). To control for the False Discovery Rate we corrected original $P$-values with the BenjaminiHochberg [65] formula as recommended by the HyPhy online discussion forum.

To test whether coding regions of $L E A F Y$ and $c G A P D H$ alleles with two or more genomic copies are under other selective regimes than alleles with one copy we estimated the ratio $(\omega)$ of the rate of nonsynonymous substitutions at non-synonymous sites $(\mathrm{dN})$ to synonymous substitutions at synonymous sites (dS). The estimates of $\omega$ indicate whether an allele is under purifying selection $(\omega<1)$, positive selection $(\omega>1)$ or evolves neutrally $(\omega=1)$. We conducted the analyses based on an alignment of consensus sequences of the coding region of $L E A F Y$ and $c G A P D H$ alleles and an unrooted topology of them using the program codeml from the PAML package [66,67]. LRT was employed to test, whether the model assuming different $\omega$ 's for the allele with two or more copies than alleles with one copy (alternative hypothesis) fits better to the data than the model assuming the same $\omega$ for all sequences (null hypothesis).

\section{Allele-specific transcription}

Allele-specific single nucleotide polymorphisms (SNPs) in the coding region were used to estimate the frequency of the different alleles in cDNA pools by pyrosequencing as a measure for their specific transcription. Suitable pyrosequencing templates containing allelespecific SNPs were deduced from alignments of $L E A F Y$, $c G A P D H$ and $n r I T S-1$, respectively. We analysed the same SNPs in genomic DNA to control for the copy number of alleles in the plants. The expected frequency in genomic DNA of an allele-specific base at a SNP is 0.2 for an allele with one copy, 0.4 for an allele with two copies and 0.6 for an allele with three copies in pentaploid individuals. These expected frequencies represent the null hypothesis of equal transcription of all alleles referring to their copy number. Three PCR products from cDNA pools of small and large flower buds of the individuals H13, H19 and H20 were amplified with primers presented in additional file 6 according to the cycling programs mentioned above. To control for contamination of RNA extracts with genomic DNA we performed PCR reactions using RNA extracts directly. Additionally, two PCR products from genomic DNA of the same plants were generated.

Template generation was done as described previously [68]. Briefly, purified PCR products were ligated into the vector pCR2.1-TOPO (Invitrogen, Karlsruhe, Germany). The recombinant DNA was used as template in a second PCR using universal biotin-labelled primers bt-f or bt-r 
and sequence specific pyrosequencing primers (additional file 7). Purification of biotin-labelled ssDNA was done using streptavidin Sepharose (Biotage, Uppsala, Sweden). Sequencing reaction and allele frequency determination was carried out on a PSQ96 MA machine (Biotage) following the manufacturer's instruction.

\section{Statistics}

Statistical tests were performed with SPSS v. 17.0. To test the influence of bud age and the investigated individual on transcription levels of alleles we performed Univariate ANOVA for each SNP in each locus. We detected a significant impact of the individuals but no significant impact of bud age on transcription level (data not shown). Thus we performed General Linear Model (GLM) analysis with "individual" as random factor to test whether allele frequency measured in genomic DNA differs significantly from allele frequency measured in cDNAs for each SNP in each locus. In cases where genomic allele composition differed between individuals we performed the tests separately.

\section{Additional material}

\section{Additional file 1: Southern hybridization experiments. \\ Additional file 2: Pairwise comparison between allele frequencies of genomic DNA and cDNA applying General Linear Model (GLM). \\ Additional file 3: Relative Rate Test (RRT). \\ Additional file 4: Single nucleotide polymorphisms (SNP) suitable for pyrosequencing in LEAFY. CGAPDH and nrITS- 1 . \\ Additional file 5: Results of Akaike information criterion (AIC). \\ Additional file 6: Primer sequences for the amplification of primary PCR products from CDNA.}

Additional file 7: Primer sequences used for pyrosequencing analysis.

\begin{abstract}
Acknowledgements
We thank T. Krügel and D. Schnabelrauch (Max Planck Institute for Chemical Ecology, Jena, Germany) for help with flow cytometry and DNA sequencing, M. Platzer (Leibniz Institute for Age Research - Fritz Lipmann Institute, Jena, Germany) for help with pyrosequencing, M. Sandmann, F. H. Hellwig (Institute of Systematic Botany, Friedrich Schiller University, Jena, Germany), A. Härter, R. Melzer (Department of Genetics, Friedrich Schiller University), M. Krauss (student assistant, Friedrich Schiller University) for excellent technical assistance, M. Ritz (Senckenberg Museum of Natural History Görlitz,

Germany) for help with statistics. The work was funded by a grant from the Deutsche Forschungsgemeinschaft (Wi 2028/1-3) under the DFG priority programme 1127 "Radiations - Origins of Biological Diversity". We thank the three anonymous reviewers for very valuable comments on the manuscript.
\end{abstract}

\section{Author details}

'Department of Botany, Senckenberg Museum of Natural History Görlitz, Am Museum 1, D-02826 Görlitz, Germany. ${ }^{2}$ Ziegenhainer Straße 19, D-07749 Jena, Germany. ${ }^{3}$ Genome Analysis, Leibniz Institute for Age Research - Fritz Lipmann Institute, Beutenbergstraße 11, D-07745 Jena, Germany.

${ }^{4}$ Department of Genetics, Friedrich Schiller University Jena, Philosophenweg

12, D-07743 Jena, Germany. ${ }^{5}$ Department of Systematic Botany, Institute of
Botany, Justus Liebig University Gießen, Heinrich-Buff-Ring 38, D-35392 Gießen, Germany,

\section{Authors' contributions}

CMR, IK and MG carried out the molecular genetic studies, CMR, GT and WW participated in the design of the study. CMR drafted the manuscript. All authors read and approved the manuscript.

Received: 25 November 2010 Accepted: 23 February 2011 Published: 23 February 2011

\section{References}

1. Hegarty MJ, Hiscock SJ: The complex nature of allopolyploid plant genomes. Heredity 2009, 103(2):100-101.

2. Soltis PS, Soltis DE: The role of hybridization in plant speciation. Annu Rev Plant Biol 2009, 60:561-588.

3. Chen ZJ, Ni ZF: Mechanisms of genomic rearrangements and gene expression changes in plant polyploids. Bioessays 2006, 28(3):240-252.

4. Semon M, Wolfe KH: Consequences of genome duplication. Curr Opin Genet Dev 2007, 17(6):505-512.

5. Chen ZJ: Genetic and epigenetic mechanisms for gene expression and phenotypic variation in plant polyploids. Bioessays 2007, 58:377-406.

6. Rapp RA, Udall JA, Wendel JF: Genomic expression dominance in alloployploids. BMC Biol 2009, 7(18).

7. Comai $L$ : The advantages and disadvantages of being polyploid. Nat Rev Genet 2005, 6(11):836-846.

8. Grant V: Plant speciation. New York, London: Columbia University Press; 1971.

9. Ritz CM, Schmuths H, Wissemann V: Evolution by reticulation: European dogroses originated by multiple hybridization across the genus Rosa. $J$ Hered 2005, 96:4-14.

10. Blackburn K, Harrison JHW: The status of the British rose forms as determined by their cytological behaviour. Ann Bot 1921, 35(138):159-188.

11. Blackburn KB: Chromosomes and classification in the genus Rosa. Am Nat 1925, 59:200-204.

12. Täckholm G: On the cytology of the genus Rosa. A preliminary note. Svensk Bot Tidskr 1920, 14(2-3):300-311.

13. Täckholm G: Zytologische Studien über die Gattung Rosa. Acta Horti Berg 1922, 7:97-381.

14. Pala I, Coelho MM, Schartl M: Dosage compensation by gene-copy silencing in a triploid hybrid fish. Curr Biol 2008, 18(17):1344-1348.

15. Henker H: Rosa. In Gustav Hegi: Illustrierte Flora von Mitteleuropa. Volume IVI 2C. Edited by: Conert HJ, Jäger EJ, Kadereit JW, Schultze-Motel W, Wagenitz G, Weber HE. Berlin: Parey; 2000:1-108.

16. Nybom H, Esselink GD, Werlemark G, Leus L, Vosman B: Unique genomic configuration revealed by microsatellite DNA in polyploid dogroses, Rosa sect. Caninae. J Evol Biol 2006, 19(2):635-648.

17. Nybom H, Esselink GD, Werlemark G, Vosman B: Microsatellite DNA marker inheritance indicates preferential pairing between two highly homologous genomes in polyploid and hemisexual dog-roses, Rosa L. sect. Caninae DC. Heredity 2004, 92(3):139-150

18. Ritz CM, Wissemann V: Microsatellite analyses of artificial and spontaneous dogrose hybrids reveal the hybridogenic origin of Rosa micrantha by the contribution of unreduced gametes. J Hered 2011.

19. Kovařik A, Werlemark G, Leitch AR, Souckova-Skalická K, Lim YK, Khaitová L, Koukalová B, Nybom $\mathrm{H}$ : The asymmetric meiosis in pentaploid dogroses (Rosa sect. Caninae) is associated with a skewed distribution of rRNA gene families in the gametes. Heredity 2008, 101(4):359-367.

20. Khaitová $L$, Werlemark $G$, Nybom $H$, Kovař́k A: Frequent silencing of rDNA loci on the univalent-forming genomes contrasts with their stable expression on the bivalent-forming genomes in polploid dogroses (Rosa sect. Caninae). Heredity 2010, 104:113-120.

21. Weigel D, Alvarez J, Smyth D, Yanosfky MF, Myerowitz EM: LEAFY controls floral meristem identity in Arabidopsis. Cell 1992, 69:843-859.

22. Lim KY, Werlemark $G$, Matyášek $R$, Bringloe JB, Sieber $V$, El Mokadem $H$, Meynet J, Hemming J, Leitch AR, Roberts AV: Evolutionary implications of permanent odd polyploidy in the stable sexual, pentaploid of Rosa canina L. Heredity 2005, 94(5):501-506.

23. Ma Y, Crane CF: Karyotypic relationships among some Rosa species. Caryologia 1997, 50(3-4):317-326. 
24. Wissemann V: Hybridization and the evolution of the nrITS spacer region In Plant Genome: Biodiversity and evolution. Volume 1. Edited by: Sharma AK, Sharma A. Enfield (USA): Science Publishers, Inc; 2003:(part A):57-71.

25. Wissemann $\mathrm{V}$ : Molecular evidence for allopolyploid origin in the Rosa canina-complex (Rosaceae, Rosoideae). J Appl Bot 2002, 76:176-178.

26. Kovařik A, Matyášek R, Lim KY, Skalická K, Koulaková B, Knapp S, Chase MW, Leitch AR: Concerted evolution of 18-5.8-26 S rDNA repeats in Nicotiana allotetraploids. Biol J Linn Soc 2004, 82(4):615-625.

27. Joly S, Starr JR, Lewis WH, Bruneau A: Polyploid and hybrid evolution in roses east of the Rocky Mountains. Am J Bot 2006, 93(3):412-425.

28. Sang T, Crawford DJ, Stuessy TF: Documentation of reticulate evolution in peonies (Paeonia) using internal transcribed spacer sequences of nuclear ribosomal DNA - implications for biogeography and concerted evolution. Proc Natl Acad Sci USA 1995, 92(15):6813-6817.

29. Smedmark JEE, Eriksson T, Evans RC, Campbell CS: Ancient allopolyploid speciation in Geinae (Rosaceae): Evidence from nuclear granule-bound starch synthase (GBSSI) gene sequences. Syst Biol 2003, 52(3):374-385.

30. Clarkson JJ, Kelly LJ, Leitch AR, Knapp S, Chase MW: Nuclear glutamine synthetase evolution in Nicotiana: Phylogenetics and the origin of allotetraploid and homoploid (diploid) hybrids. Mol Phylogenet Evol 2010, 55:99-112.

31. Tate JA, Ni ZF, Scheen AC, Koh J, Gilbert CA, Lefkowitz D, Chen ZJ, Soltis PS Soltis DE: Evolution and expression of homeologous loci in Tragopogon miscellus (Asteraceae), a recent and reciprocally formed allopolyploid. Genetics 2006, 173(3):1599-1611.

32. Koh J, Soltis DE, Soltis PS: Homeolog loss and expression changes in natural populations of recently and repeatedly formed allotetraploid Tragopogon mirus (Asteraceae). BMC Genomics 2010, 11(97)

33. Song K, Lu P, Tang K, Osborn TC: Rapid genome change in synthetic polyploids of Brassica and its implications for polyploid evolution. Proc Natl Acad Sci USA 1995, 92:7719-7723.

34. Tate JA, Joshi P, Soltis KA, Soltis PS, Soltis DE: On the road to diploidization? Homoeolog loss in independently formed populations of the allopolyploid Tragopogon miscellus (Asteraceae). BMC Plant Biol 2009, 9(80).

35. Feldman M, Liu B, Segal G, Abbo S, Levy AA, Vega JM: Rapid elimination of low-copy DNA sequences in polyploid wheat: A possible mechanism for differentiation of homoeologous chromosomes. Genetics 1997, 147(3):1381-1387.

36. Cronn RC, Small RL, Wendel JF: Duplicated genes evolve independently after polyploid formation in cotton. 1999, 96(25):14406-14411.

37. Wendel JF: Genome evolution in polyploids. Plant Molec Biol 2000, 42(1):225-249.

38. Joly S, Rauscher JT, Sherman-Broyles SL, Brown AHD, Doyle JJ: Evolutionary dynamics and preferential expression of homeologous 18S-5.8S-26 S nuclear ribosomal genes in natural and artificial Glycine allopolyploids. Mol Biol Evol 2004, 21(7):1409-1421.

39. Wendel JF, Schnabel A, Seelanan T: Bidirectional interlocus concerted evolution following allopolyploid speciation in cotton (Gossypium). Proc Natl Acad Sci USA 1995, 92(1):280-284

40. Kovařik A, Dadejova M, Lim YK, Chase MW, Clarkson JJ, Knapp S, Leitch AR: Evolution of rDNA in Nicotiana allopolyploids: A potential link between rDNA homogenization and epigenetics. Ann Bot 2008, 101(6):815-823.

41. Matyášek R, Tate JA, Lim YK, Šrubařová H, Koh J, Leitch AR, Soltis DE, Soltis PS, Kovařik A: Concerted evolution of rDNA in recently formed Tragopogon allotetraploids is typically associated with an inverse correlation between gene copy number and expression. Genetics 2007, 176:2509-2519.

42. Zylstra P, Rothenfluh HS, Weiller GF, Blanden R, Steele EJ: PCR amplification of murine immunoglobulin germline $V$ genes: strategies for minimization of recombination artefacts. Immunol Cell Biol 1998, 76:395-405.

43. Salmon A, Flagel L, Ying B, Udall JA, Wendel JF: Homoeologous nonreciprocal recombination in polyploid cotton. New Phytol 2010, 186(1):123-134.

44. Kovařik A, Pires JC, Leitch AR, Lim KY, Sherwood AM, Matyášek R, Rocca J, Soltis DE, Soltis PS: Rapid concerted evolution of nuclear ribosomal DNA in two Tragopogon allopolyploids of recent and recurrent origin. Genetics 2005, 169(2):931-944.

45. Dadejova M, Lim KY, Souckova-Skalická K, Matyášek R, Grandbastien MA, Leitch A, Kovařik A: Transcription activity of rRNA genes correlates with a tendency towards intergenomic homogenization in Nicotiana allotetraploids. New Phytol 2007, 174(3):658-668.

46. Flagel L, Udall J, Nettleton D, Wendel J: Duplicate gene expression in allopolyploid Gossypium reveals two temporally distinct phases of expression evolution. BMC Biol 2008, 6.

47. Adams KL, Cronn R, Percifield R, Wendel JF: Genes duplicated by polyploidy show unequal contributions to the transcriptome and organspecific reciprocal silencing. Proc Natl Acad Sci USA 2003, 100(8):4649-4654

48. Adams KL, Percifield R, Wendel JF: Organ-specific silencing of duplicated genes in a newly synthesized cotton allotetraploid. Genetics 2004, 168(4):2217-2226.

49. Wang JL, Tian L, Lee HS, Wei NE, Jiang HM, Watson B, Madlung A, Osborn TC, Doerge RW, Comai L, et al: Genomewide nonadditive gene regulation in Arabidopsis allotetraploids. Genetics 2006, 172(1):507-517.

50. Chen ZJ, Pikaard CS: Transcriptional analysis of nucleolar dominance in polyploid plants: Biased expression/silencing of progenitor rRNA genes is developmentally regulated in Brassica. Proc Natl Acad Sci USA 1997, 94(7):3442-3447

51. Liu ZL, Adams KL: Expression partitioning between genes duplicated by polyploidy under abiotic stress and during organ development. Curr Biol 2007, 17:1669-1674.

52. Slomovic S, Laufer D, Geiger D, Schuster G: Polyadenylation of ribosomal RNA in human cells. Nucleic Acids Res 2006, 34(10):2966-2975.

53. Zielinski J: Studia nad rodzajem Rosa L. Systematyka sekcji Caninae DC. em Christ. Arboretum Kórnickie Rocznik 1985, 30:3-109.

54. Kvaček Z, Walther H: Oligocene flora of Bechlejovice at Děčin from the neovolcanic area of the České Středhoří Mountains, Czech Republic. Acta Musesei Nationalis Pragae, Series B, Natural History 2004, 60(1-2):9-60.

55. Yokoya K, Roberts V, Mottley J, Lewis R, Brandham PE: Nuclear DNA amounts in roses. Ann Bot 2000, 85:557-561.

56. Xu Q, Wen X, Deng X: A simple method for isolating genomic DNA from chestnut rose (Rosa roxburghii Tratt) for RFLP and PCR analyses. Plant Mol Biol Rep 2004, 22:301-310.

57. Dhanaraj AL, Slovin JP, Rowland LJ: Analysis of gene expression associated with cold acclimation in blueberry floral buds using expressed sequence tags. Plant Sci 2004, 166(4):863-872.

58. White TJ, Lee $S, J T$ : Amplification and direct sequencing of fungal ribosomal RNA genes for phylogenetics. In PCR protocols A guide to methods and applications. Edited by: Innis MA, Gelfand DH, Sninsky JJ, White JW. New York: Academic Press; 1990:315-322.

59. Hall T: BioEdit: a user-friendly biological sequence alignment editor and analysis program for Windows 95/98/NT. Nucl Acids Symp Ser 1999, 41:95-98.

60. Nylander JAA: MrModeltest v2. Uppsala Evolutionary Biology Centre, Uppsala University; 2004, Program distributed by the author.

61. Huelsenbeck JP, Ronquist F: MRBAYES: Bayesian inference of phylogeny. Bioinformatics 2001, 17:754-755

62. Clement M, Posada D, Crandall KA: TCS: a computer program to estimate gene genealogies. Molec Ecol 2000, 9:1657-1659.

63. Pond SLK, Frost SDW, Muse SV: HyPhy: hypothesis testing using phylogenies. Bioinformatics 2005, 21(5):676-679.

64. Muse SV, Gaut BS: A likelihood approach for comparing synonymous and nonsynonymous nucleotide substution rates, with applications to the chloroplast genome. Mol Biol Evol 1994, 11(5):715-724.

65. Benjamini $Y$, Hochberg $Y$ : Controlling the false discovery rate - a practical and powerful approach to multiple testing. J R Stat SoC B 1995, 57(1):289-300

66. Yang ZH: PAML: a program package for phylogenetic analysis by maximum likelihood. Comput Appl Biosci 1997, 13(5):555-556.

67. Yang ZH: PAML 4: a program package for phylogenetic analysis by maximum likelihood. Mol Biol Evol 2007, 24:1586-1591.

68. Groth M, Huse K, Reichwald K, Taudien S, Hampe J, Rosenstiel P, Birkenmeier G, Schreiber S, Platzer M: Method for preparing singlestranded DNA templates for pyrosequencing using vector ligation and universal biotinylated primers. Anal Biochem 2006, 356(2):194-201.

doi:10.1186/1471-2229-11-37

Cite this article as: Ritz et al:: To be or not to be the odd one out Allele-specific transcription in pentaploid dogroses (Rosa L. sect. Caninae (DC.) Ser). BMC Plant Biology 2011 11:37. 